\title{
1 Hydroxypropylation improves film properties of high amylose corn starch
}

2 Hee-Young Kim ${ }^{\text {a }}$, Jay-lin Jane ${ }^{\text {a }}$, Buddhi Lamsal ${ }^{\text {* }}$

3

4

${ }^{a}$ Department of Food Science and Human Nutrition, Iowa State University, Ames, IA

5 50011, USA

6

7

8

9

10

11

12

13

14

15

16

17

18

19

20

$21{ }^{*}$ Corresponding author. Tel: +1 515294 8681; Fax: +1 5152948181.

22

E-mail address:lamsal@iastate.edu (B. Lamsal)

23

24

25 
Abstract

Important characteristics of solvent-cast films prepared with modified high amylose corn starch were compared. The hydroxypropylation of high amylose corn starch with propylene oxide at $3-12 \%(\mathrm{w} / \mathrm{w}$ starch basis) and glycerol as plasticizer reduced film brittleness. Increasingly intact and transparent films with higher elongation at break $(E)$ were obtained with higher concentrations of propylene oxide- $E$ increased from 37.55 to $63.37 \%$ for 3 and $12 \%$ propylene oxide, respectively. However, corresponding tensile strength (TS) of the films decreased from 15.98 $\mathrm{MPa}$ to 8.85 $\mathrm{MPa}$. Plasticizer types (glycerol, sorbitol, xylitol, and mixtures of glycerol/sorbitol or glycerol/xylitol) and contents (10-25\%, w/w of starch) strongly affected the film formation and characteristics of hydroxypropylated high amylose corn starch. The hydroxypropylation with $6 \%(\mathrm{w} / \mathrm{w})$ propylene oxide (6HPHACS) and $20 \%(\mathrm{w} / \mathrm{w})$ glycerol resulted in optimal cast-films, based on both appearance and mechanical properties. These films exhibited better flexibility with adequate tensile strength and water vapor permeability.

\section{Keywords}

Cast-film; High amylose corn starch; Hydroxypropylation; Mechanical properties 


\section{Introduction}

Utilizing renewable resources for industrial applications has become an important consideration due to economic and environmental concerns, for example, development of biodegradable plastics from renewable biopolymers. Starch is one such promising resource for biopolymer applications due to its abundance, renewability, low cost (0.25-0.6 dollar per $\mathrm{kg})$, and thermoplasticity (Lai and Padua, 1997; Chiellini et al., 2009; Mali et al., 2005a).

Granular starch has a semi-crystalline structure consisting of concentric alternating amorphous and semi-crystalline growth rings (French, 1984). The crystalline structure needs to be disrupted for starch to function as a film. This can be done in the presence of water and heat resulting in a homogeneous melt with thermoplastic properties (Shanks and Kong, 2012; Zdrahala, 1997). Conventional processing techniques, e.g., solvent-casting, extrusion-blowing, and injection or compression molding, have been adapted to obtain thermoplastic starch (TPS) (Van Soest., 1996).

Thermoplastic starches from various sources, e.g., rice, cassava, corn, and potato, etc. have been studied in the past for packaging applications; however, they exhibit several shortcomings such as brittleness, lower mechanical properties and higher water sensitivity. Zhang et al. (2014b) summarized properties of some TPS films made from unmodified starches. Tensile strength of films was typically less than $5 \mathrm{MPa}$ with corresponding water vapor permeability up to $748.80 \mathrm{~g} \mathrm{~mm} \mathrm{~m}^{-2} \mathrm{day}^{-1} \mathrm{kPa}^{-1}$. Low-density polyethylene (LDPE), which is one of the most widely used synthetic polymers, was reported to have a tensile strength of 7.6017.30 MPa and water vapor permeability of $0.08 \mathrm{~g} \mathrm{~mm} \mathrm{~m}^{-2}$ day $^{-1} \mathrm{kPa}^{-1}$ (Briston, 1988).

Selecting starch sources with higher amylose content could be one way of overcoming said drawbacks in starch-based films. Several studies (Lopez and Garcia, 2012; Phan et al., 2005; Myllärinen et al., 2002; Muscat et al., 2012) have shown that starch films with higher 
apparent amylose content (up to 80\%) were stronger and more water resistant than those with normal corn starch (apparent amylose content ca. 28\%) (Van Soest et al., 1996). Nevertheless, the use of high amylose starch for film applications is rather limited, mostly, due to its high melt viscosity (Thunwall et al., 2006), which is related to inherent high melting temperature of amylose (Shogren, 1992). There are a few studies on the use of native high amylose starches, and films have been mostly produced by extrusion under higher pressures and temperatures (Thuwall et al., 2006; Chaudhary et al., 2009). Chemical modifications of starch may lend them amenable to film formation at lower temperatures and pressures.

The hydroxypropylation is one such chemical modification that results in starch ether when starch and propylene oxide are reacted (Tsuzuki, 1968). Hydroxypropyl group ($\mathrm{CH}_{2} \mathrm{CHOHCH}_{3}$ ) disrupts hydrogen bonds in the starch so that weakened starch can be more easily accessible to water (Wootton and Manatsathit, 1983; Wootton and Manatsathit, 1984). The gelatinization temperatures $\left(\mathrm{T}_{\mathrm{o}}, \mathrm{T}_{\mathrm{p}}\right.$, and $\left.\mathrm{T}_{\mathrm{c}}\right)$ and enthalpies $(\Delta H)$ of hydroxypropylated starches are lower than those of native starch and is related to the degree of substitution. Peak gelatinization temperatures $\left(\mathrm{T}_{\mathrm{p}}\right)$ of normal maize starch were $68,60,54$ and $50^{\circ} \mathrm{C}$ after hydroxypropylation with $0,4,12$, and $16 \mathrm{~mL}$ of propylene oxide (200 g dry starch basis), respectively (Wootton and Manatsathit, 1984). Lower gelatinization temperatures allow easy formation of hydroxypropylated high amylose starch films.

Rice (30\% apparent amylose), potato (86\% apparent amylose), and pea (34\% apparent amylose) starches have been used for preparation of high amylose starch films (Woggum et al., 2015; Jansson and Järnström, 2005; Lafargue et al., 2007). Use of high-amylose corn starch can also be found in the literature (Zhang et al., 2013 a, b; Gilfillan et al., 2013; Dean et al., 2011; Isotton et al., 2015; Chaudhary et al., 2009; Bae and Lim, 1998). However, there is no information about properties of hydroxypropylated high amylose corn starch films as affected 
by propylene oxide levels. Thus, the aim of this study is to evaluate the effect of propylene oxide levels on solvent-cast films from high amylose corn starch (75\% apparent amylose). The properties of optimally hydroxypropylated high amylose corn starch (HPHACS) were further investigated, e.g., optical, mechanical, and barrier properties with different plasticizers types and contents.

\section{Materials and methods}

\subsection{Materials}

Normal corn starch (NCS, PURE-DENT B700) was provided by Grain Processing Corporation (Muscatine, IA, USA). High amylose corn starch (HACS, AmyloGel ${ }^{\mathrm{TM}}$ ) containing 75\% apparent amylose was provided by Cargill (Minneapolis, MN, USA). Glycerol, sorbitol, xylitol, propylene oxide, and magnesium nitrate $\left(\mathrm{Mg}\left(\mathrm{NO}_{3}\right)_{2}\right)$ were purchased from Fisher Scientific (Fair Lawn, NJ, USA). All other chemical reagents used were of analytical grade.

\subsection{Hydroxypropylation (HP) of high amylose corn starch (HACS)}

Hydroxypropylation reaction for high amylose corn starch (HPHACS) followed the procedures as described by Wootton and Manatsathit (1983) with some modifications. HACS (80 g, dry solids) was dispersed in distilled water $(640 \mathrm{~mL})$ containing anhydrous sodium sulfate $(8 \%$, w/w of starch), and $\mathrm{pH}$ adjusted to 11.5 using $1 \mathrm{M} \mathrm{NaOH}$. Various amounts of propylene oxide $(3,6$, and $12 \%$, w/w of starch) were added dropwise to slurry with vigorous stirring at room temperature. The reaction bottle was sealed tightly and shaken in a water bath $\left(150 \mathrm{rpm}, 45^{\circ} \mathrm{C}\right)$ for $20 \mathrm{~h}$. Starch slurry was then neutralized to $\mathrm{pH} 5.5$ by adding $1 \mathrm{M} \mathrm{HCl}$. The recovered starch after centrifugation (1500 $\mathrm{x} g$ for $20 \mathrm{~min}$ ) was washed with distilled water (3 
$\mathrm{X}$ ), and dried at $40^{\circ} \mathrm{C}$ for $24 \mathrm{~h}$. The dried starch was passed through an ASTM E-11 standard sieve (aperture $300 \mu \mathrm{m}$ ) and used for solvent casting of films.

The hydroxypropyl substitution (\%) of starch was determined by using spectrophotometric method (Johnson, 1969). the moles of substituent per mole of anhydroglucose unit (MS) was calculated as:

$\mathrm{MS}=162 \mathrm{~W} / 100 \mathrm{M}-(\mathrm{M}-1) \mathrm{W}$

where, $\mathrm{W}$ is equivalent hydroxypropyl group in $100 \mathrm{mg}$ of starch, $\mathrm{M}$ is molecular weight of propylene oxide $\left(\mathrm{C}_{3} \mathrm{H}_{6} \mathrm{O}\right)$.

\subsection{Thermal properties of HPHACS}

Gelatinization properties of HPHACS were measured using differential scanning calorimeter (DSC 7, Perkin-Elmer, Norwalk, CT, USA). Starch (3 mg, dry solids) was weighted into an aluminum pan with $9 \mu \mathrm{L}$ of distilled water. The pan was sealed and equilibrated at room temperature for $2 \mathrm{~h}$ and then heated from 20 to $130^{\circ} \mathrm{C}$ at a heating rate of $10^{\circ} \mathrm{C} / \mathrm{min}$ with an empty pan as reference. The analysis was done in duplicate.

\subsection{Solvent casting of starch films}

All starches used in this study were defatted first, as presence of lipid in the starch was reported to reduce the maximum elongations of films (Bader and Göritz, 1994). Native and hydroxypropylated starches (9 g, dry solids) dispersed in aqueous DMSO solution $(90 \%$, w/v, $300 \mathrm{~mL}$ ) were heated in boiling water bath for $1 \mathrm{~h}$, and continuously stirred overnight at room temperature. Precipitated starch was washed with absolute ethyl alcohol $(250 \mathrm{~mL} \times 2$ times) (Klucinec and Thompson, 1998). No amylose-lipid complex peak was detected following this treatment. The purified wet starch was dispersed in hot water $\left(60^{\circ} \mathrm{C}, 20 \mathrm{~mL} / \mathrm{g}\right.$ of dry starch). 
Aliquot of hot water was added into calculated amount of plasticizers on starch weight basis $(10,15,20$, and $25 \%$ glycerol, sorbitol, xylitol, and 50:50 mixtures of glycerol/sorbitol or glycerol/xylitol) and stirred for $20 \mathrm{~min}$ for full dissolution of plasticizer in hot water. The plasticizer solution was added into starch solution and mixed in a water bath at $100^{\circ} \mathrm{C}$ for $1 \mathrm{~h}$ with vigorous stirring. In the case of native high amylose corn starch, additional autoclaving at $130^{\circ} \mathrm{C}$ was done for $20 \mathrm{~min}$. The hot solution was centrifuged at $1500 \times \mathrm{g}$ for $1 \mathrm{~min}$ to remove air bubbles. The solution $(136 \mathrm{~mL})$ was cast onto glass-plates $(155 \times 205 \mathrm{~mm})$ placed on a level wood slab, and cooled down for $2 \mathrm{~h}$ followed by drying at $50^{\circ} \mathrm{C}$ overnight. Dried films were peeled from the glass-plates and used for further analysis.

\subsection{Characterization of cast films}

\subsubsection{Thickness}

The film thickness was determined using an electronic digital caliper (Marathon, Ontario, Canada) with an accuracy of $0.01 \mathrm{~mm}$. The rectangular film specimens $(20 \times 68 \mathrm{~mm})$ were equilibrated at $25{ }^{\circ} \mathrm{C}$ for 2 days in a sealed chamber at $53 \% \mathrm{RH}$ maintained with saturated solution of magnesium nitrate (Wexler and Hasegawa, 1954). Thickness of the equilibrated films was measured at 3 random positions and average values reported.

\subsubsection{Transparency}

Starch film transparency was measured following method described by Li et al. (2015). A rectangular specimen $(10 \times 3.5 \mathrm{~mm})$ was placed in a spectrophotometer cell. The absorbance was measured at $600 \mathrm{~nm}$ using the UV-vis spectrophotometer (Shimadzu UV-160, Japan). Three replicates for each film specimen were done and the average values reported. Film transparency was calculated by dividing the absorbance with thickness (mm). The higher transparency value indicated lower transparency. 


\subsubsection{Mechanical properties: Tensile test}

Mechanical properties of film were measured in tension using a universal testing machine (Instron 4500 series, USA) following the ASTM D882-02 guideline (2002). The rectangular specimens $(20 \times 68 \mathrm{~mm})$ were equilibrated at $25^{\circ} \mathrm{C}$ and $53 \% \mathrm{RH}$ for 2 days, prior to testing. Initial grip distance and crosshead speed were $50 \mathrm{~mm}$ and $50 \mathrm{~mm} / \mathrm{min}$, respectively. Tensile strength (TS, MPa) was obtained by dividing the maximum load with specimen cross-sectional area. Elongation at break $(E, \%)$ was defined as the percent change in specimen length over the length between the grips at break (Muscat et al., 2012). At least 5 specimens were tested for each film sample.

\subsubsection{Fourier transform infrared (FT-IR)}

FT-IR analysis of starch films was done for evaluating interactions between film components (starch and plasticizer). Absorbance spectra of the films were acquired using a Tension 37 FTIR spectrophotometer (Bruker Co., Ettlingen, Germany) in attenuated total reflectance (ATR) mode. Films conditioned at $25^{\circ} \mathrm{C}$ and $53 \% \mathrm{RH}$ for 2 days were placed on the zinc selenide crystal $(10 \times 45 \times 4 \mathrm{~mm})$. The spectra were obtained in $400-4000 \mathrm{~cm}^{-1}$ range by accumulation of 16 scans at $4 \mathrm{~cm}^{-1}$ resolution. Area measurements and baseline corrections were carried out using OPUS 7.2.139 software (Bruker Co., Ettlingen, Germany).

\subsubsection{Moisture content}

Moisture content of films was determined by measuring the weight loss $(20 \times 20 \mathrm{~mm})$ upon drying in a convection oven at $110^{\circ} \mathrm{C}$ until a constant dry weight was reached (Ghasemlou et al., 2013). At least duplicate samples for each film was used to measure the moisture content.

\subsubsection{Water vapor permeability}

Water vapor permeability (WVP) of starch films was determined gravimetrically using the dry cup method following ASTM D1653-13 guideline (2013). The test cup (Elcometer 
5100, Payne permeability cup, Argenteau, Belgium) was filled with desiccant (calcium sulfate) to produce $0 \% \mathrm{RH}$ and covered with film sample (diameter: $76.2 \mathrm{~mm}$ ). The cup was fixed with four screws and placed in the chamber (ESPEC EPL-3H, Hudsonville, MI, USA) with 400 cubic feet per min airflow. The temperature and relative humidity of the chamber were $23^{\circ} \mathrm{C}$ and $50 \%$, respectively. Water vapor transport into the cup was determined by the weight gained by desiccant in the cup. The cup was weighed to the nearest $0.1 \mathrm{mg}$ periodically. Linear regression was used to fit the data, weight vs. time, to calculate the slope of the linear portion of the plot, which represents the steady state amount of water vapor diffusing through the film per unit time. The average time frame of the linear region was $50 \mathrm{~h}$. The water vapor transmission rate (WVTR) was calculated from the slope of the linear portion, $\Delta W / \Delta t$, divided by the film area $(A)$ as Eq. (1), $\left(\mathrm{g} \mathrm{day}^{-1} \mathrm{~m}^{-2}\right)$.

$\mathrm{WVTR}=\Delta W /(\Delta t \cdot A)$,

Where, $\Delta W$ is the weight of water absorbed in the test cup $(\mathrm{g}), \Delta t$ is the time for weight change (day), $A$ is the area exposed to moisture transfer $\left(\mathrm{m}^{2}\right)$. The water vapor permeability (WVP) was calculated as Eq. (2), (g mm day $\left.{ }^{-1} \mathrm{kPa}^{-1}\right)$

$\mathrm{WVP}=(\mathrm{WVTR} \times L) / \Delta p$,

Where, $L$ is the thickness of the film $(\mathrm{mm})$ and $\Delta p$ is the difference of partial water vapor pressure across the film $\left(\Delta p=p\left(\mathrm{RH}_{2}-\mathrm{RH}_{1}\right),(\mathrm{kPa})\right.$, where $p$ is the saturation vapor pressure of water at $23^{\circ} \mathrm{C}, \mathrm{RH}_{1}=0 \%, \mathrm{RH}_{2}=50 \%$. At least duplicate samples for each film was used to measure the water vapor permeability.

\subsubsection{Oxygen permeability}

Oxygen transmission rate of films was determined according to ASTM D3985-05 guideline (2010) using an Mocon OX-TRAN 2/20 (Minneapolis, MN, USA). The film sample equilibrated at $50 \% \mathrm{RH}$ and $23^{\circ} \mathrm{C}$ for 2 days was placed on a stainless-steel mask with open 
226

227

228

229

230

231

232

233

234

235

236

237

238

239

240

241

test area of $5 \mathrm{~cm}^{2}$. Different gases passed on either side of the film- oxygen (100\%) passed on one side of the film and nitrogen $\left(98 \% \mathrm{~N}_{2}\right.$ and $\left.2 \% \mathrm{H}_{2}\right)$ on the other side. After leaving the sample chamber, nitrogen gas passed over to the coulometric oxygen sensor to measure oxygen concentration in nitrogen gas.

Oxygen permeability (OP) was calculated by dividing oxygen transmission rate by the difference in oxygen partial pressure between both sides of the film and multiplying by the average thickness of the film. Measurements were performed in duplicate at least and the unit for OP was $\mathrm{cm}^{3} \mu \mathrm{m} \mathrm{m}^{-2}$ day $^{-1} \mathrm{kPa}^{-1}$.

\subsection{Statistical analysis}

Statistical analysis consisted of an analysis of variance (ANOVA) using SAS 9.4 software (SAS Institute, Cary, NC, USA). Duncan's multiple range test $(p<0.05)$ was done to identify statistical differences between mean values.

1




\section{Results and Discussion}

\section{3-1. Film-forming ability of HACS}

Fig. 1 presents the cast-films prepared from normal corn starches with apparent amylose content $25 \%$ or $75 \%$ (Fig 1a), and hydroxypropylated starches (Fig 1b). The normal corn starch (NCS) films plasticized with $20 \%(\mathrm{w} / \mathrm{w})$ glycerol were structurally intact and had smooth surfaces (Fig 1(a)). On the other hand, high amylose corn starch (HACS) films with same amount of glycerol were brittle and cracked severely, thus, only a portion with the intact film could be used for testing.

One possible reason for severe cracking might be the different sensitivity of amylose and amylopectin to the plasticizers (Myllärinen et al., 2002), which is to decrease the inherent brittleness of starch by reducing the inter- or intra-molecular forces between starch chains, consequently, increase the flexibility of films (Souza and Andrade, 2002). Myllärinen et al. (2002) showed that amylose film was rather stronger (tensile strength of $10 \mathrm{MPa}$ ), whereas, the amylopectin film had lost its strength entirely when both films were plasticized with $30 \%$ glycerol. A similar trend was reported by Muscat et al. (2012). Elongation at break (E, \%), which generally shows a trend opposite to the tensile strength, was higher for corn starch films with lower (25\%) apparent amylose content compared to higher (80\%). Lopez and Garcia (2012) observed that films made from ahipa starch with lower (11.6\%) apparent amylose had higher $E$ values at $21.8 \%$, compared to $4.10 \%$ for starch films with higher (23.9\%) apparent amylose content. To prevent or reduce cracking in the HACS films, more plasticizer may be required compared to NCS films. In the preliminary study, it was found that when $40 \%(\mathrm{w} / \mathrm{w})$ glycerol was added with HACS, the films maintained flexibility, but were very sticky. While higher levels of plasticizers may help reduce brittleness, too much of it will produce sticky films. 


\section{3-2. Hydroxypropylation (HP) of HACS and films Properties}

To produce less brittle HACS films with minimum plasticizer, hydroxyproylation (HP) of starch was carried out. Reacting propylene oxide with starch under alkaline conditions yields starch containing hydroxypropyl groups, that is, hydroxypropylated starch (Gray and BeMiller, 2005). Prior literature (Woggum et al., 2015) had shown that hydroxypropylated rice starch films had higher elongation to break than native ones. Also, HP reduced gelatinization temperature, thus, films could be produce at lower temperatures. This is advantageous if starch with higher and broader melting temperature range like HACS is used for film (Liu et al., 2006). Table 1 shows the hydroxypropyl group (\%), molar substitutions (MS), and reaction efficiency (\%) in hydroxypropylated HACS (HPHACS) when reactedwith 3-12\% (w/w) propylene oxide, to be referred to as 3HPHACS, 6HPHACS, and 12HPHACS, respectively. Both percent hydroxypropyl groups and corresponding MS increased with the level of propylene oxide, as reported in literature (Woggum et al., 2015; Gray and BeMiller, 2005). The concentration of propylene oxide used in this study did not exceed the maximum allowable level for food applications which is less than $25 \%$, based on the dry starch weight; Food Chemicals Codex, 1972).

Fig.1(b) shows the films made with up to $12 \%$ hydroxypropylated corn starches. The cracks observed in HACS film noticeably reduced after adding 3\% (w/w of starch) propylene oxide; more propylene oxide (e.g., 6 and 12\%, w/w of starch) led to intact HACS films, with hydroxypropyl groups also likely acting as plasticizer. Plasticizer inserted among and between starch chains increases film flexibility by weakening inter- and intra-molecular hydrogen bonding between starch chains by favorably forming hydrogen bonds between hydroxyl groups $(-\mathrm{OH})$ of plasticizer and starch chains (Muscat et al., 2012). Similarly, during the hydroxypropyl groups $\left(-\mathrm{CH}_{2} \mathrm{CHOHCH}_{3}\right)$, during hydroxypropylation, interacted with starch 
chains, disrupting inter-and intra-molecular hydrogen bonds of the native starch. The extent of the disruption of hydrogen bonds between starch chains may be greater with more hydroxypropyl groups.

These observations of more flexible starches films with higher levels of HP could be related to their thermal properties. As shown in Fig. 2., both gelatinization temperatures $\left(T_{0}\right.$, $\mathrm{T}_{\mathrm{p} 1}, \mathrm{~T}_{\mathrm{p} 2}$, and $\left.\mathrm{T}_{\mathrm{c}}\right)$ and enthalpies $(\Delta H)$ of HPHACS decreased gradually with increasing levels of propylene oxide. Hydrophilic hydroxypropyl groups would facilitate water sorption into the starch, leading to lowering of gelatinization temperatures (Seow and Thevamalar, 1993). Also, hydroxypropyl groups would disrupt the double helices within the amorphous region in starch granules, owing to the rotation of flexible hydroxypropyl groups (Perera et al., 1997). As a result, enthalpies indicating loss of double helical order (Cooke and Gidely, 1992) were lower in HPHACS than in native HACS.

Mechanical properties of HPHACS films with 3-12\% (w/w of starch) propylene oxide are presented in Table 2. All films tested were in the same thickness range (0.10 to $0.12 \mathrm{~mm})$, and not significantly different. Films without propylene oxide, that is, native HACS films, showed TS of $18.90 \mathrm{MPa}$ and $E$ of $28.17 \%$, respectively. The increase in propylene oxide levels (3$12 \%$, w/w) led to decrease in film TS (from 15.98 to $8.85 \mathrm{MPa}$ ) and increase in the $E$ values (from 37.55 to $63.37 \%$ ). This result can also be explained by the role of hydroxypropyl groups in weakening the strong molecular attraction between starch chains, resulting in decreased TS of HPHACS films. The disruption of starch chains reduced rigidity and enhanced flexibility of HPHACS films by allowing increased chain mobility. Similar result was also reported for rice starch containing 30.4\% apparent amylose and hydroxypropylated with propylene oxide at 6$12 \%$ (w/w of starch). The TS and $E$ values of the films ranged from 5.53 to $3.88 \mathrm{MPa}$ and from 79.58 to $132.59 \%$, respectively, at the level of 6 and $12 \%$ of propylene oxide (w/w of starch) 
(Woggum et al., 2015).

It is noteworthy that 6HPHACS films were intact without any cracks compared to 3HPHACS films (Fig. 1b). The difference in hydroxypropyl groups (\%) influenced this morphological difference. Based on our results, the minimum level of hydroxypropyl groups required to obtain intact HACS film may be between 1.4 to $2.5 \%$. Excessive hydroxypropyl groups rather led to sharply decreased TS in films. Along with mechanical properties, transparency of HACS films was also affected by the degree of hydroxypropylation (Fig. 1(b) and Table 2). Increasing the level of propylene oxide increased film transparency, as shown by higher transmission of light across the films. It is assumed that bulky and hydrophilic hydroxypropyl groups would restrict reassociation of amylose chains (Choi and Kerr, 2004), thus, improving transparency.

\section{3-3. Effect of plasticizers on 6HPHACS films}

\section{3-3-1. Mechanical properties}

The 6HPHACS starch films were further prepared with various plasticizers and their properties were compared for effect of plasticizers. These 6HPHACS films plasticized with glycerol, sorbitol, xylitol and mixtures of glycerol/sorbitol or glycerol/xylitol at 10-25\% (w/w) levels are shown in Fig. 3. Films plasticized with 10G, 15S, 15X, 20S, 20X, and 25S cracked to varying degrees upon drying. However, films plasticized with glycerol (15G, 20G), xylitol (25X), and 50:50 mixtures glycerol/sorbitol (15GS), and glycerol/xylitol (15GX) remained almost or completely intact. This indicates the superior plasticizing ability of glycerol compared to others, as also reported in many studies (Zhang and Han, 2006b; Bertuzzi et al., 2007; Jangehud and Chinnan, 1999; Müller et al., 2008). Zhang and Han (2006a) reported efficient plasticizing ability of glycerol by comparing glass transition temperatures $\left(\mathrm{T}_{\mathrm{g}}\right)$ for pea 
starch films upon added plasticizers. The glass transition temperature $\left(\mathrm{T}_{\mathrm{g}}\right)$ of a material reflects the transition from solid to rubber to viscous liquid; at temperatures below the $T_{g}$, the material is in glassy state, and at temperatures above the $\mathrm{T}_{\mathrm{g}}$ in rubbery state (Gibson and Ashby, 1988). The glycerol-plasticized films were reported to have lower $\mathrm{T}_{\mathrm{g}}$ value $\left(-66.1^{\circ} \mathrm{C}\right)$ than those of sorbitol or monosaccharides-plasticized films $\left(-3.62 \sim-32.6^{\circ} \mathrm{C}\right)$ (Zhang and Han, 2006a). This indicates the rubbery state of glycerol-plasticized films compared to other films in our study, most likely to result in more flexible films. Plasticizing effect of glycerol was almost minimal when its concentration was relatively lower (i.e. 10G) requiring extra care to minimize cracking prior to testing.

Fig. 4 presents the effects of plasticizer types and contents on mechanical properties of 6HPHACS films. An intact specimen from the highly cracked 10G film exhibited the highest TS (33.81 MPa), but very low $E$ value (16.69\%) among tested samples. This could be explained by relatively lower amount of plasticizer (Muscat et al., 2012), which causes the rigidity, rather than flexibility of starch films, consequently, films become stiffer than without plasticizer (Chang et al., 2006).

At $15 \%$ (w/w) plasticizer level, all films exhibited similar $E$ values (16.66-16.68\%), even though the extent of the cracking was different (Fig. 3). When the plasticizer concentration increased to $20 \%$ (w/w), $E$ values between films showed significant differences. The $E$ values followed the order: $20 \mathrm{G}(39.64 \%)>20 \mathrm{X}(36.51 \%)>20 \mathrm{~S}(17.87 \%) . E$ values for $20 \mathrm{G}$ and $20 \mathrm{X}$ films increased more than 2 times, compared to $E$ for $15 \mathrm{G}$ and $15 \mathrm{X}$ films. In contrast, $E$ values for sorbitol-plasticized films almost did not change- $16.67 \%$ for $15 \mathrm{~S}$ film and $17.87 \%$ for $20 \mathrm{~S}$ film- when the concentration increased from $15 \%$ to $20 \%$ (w/w) respectively. Further increase in sorbitol content to $25 \%$ (w/w), led to increased $E$ values up to $48.01 \%$, however, it was still lower than $E$ value of $54.31 \%$ for xylitol-plasticized films at the same concentration level. 
Sorbitol was consequently considered as less efficient plasticizer than glycerol and xylitol to achieve the same degree of $E$.

The difference in plasticizing effect between sorbitol and glycerol may be attributed to their differing abilities to associate with water (Gontard et al., 1993). Sorbitol is $71 \%$ water soluble with medium to low hygroscopicity, whereas, glycerol is infinitely soluble in water at $25^{\circ} \mathrm{C}$ with a medium to high hygroscopicity (Griffin and Lynch, 1980). However, greater plasticizing effect of xylitol than sorbitol is hard to explain because they have similar solubility, even with xylitol having lower hygroscopic properties (Bär, 1991; Griffin and Lynch, 1980). One possible reason may be slightly greater xylitol molar ratio per $\mathrm{g}$ of starch than sorbitol (1.313 vs. $1.097 \mathrm{mmol} / \mathrm{g}$ of starch).

The TS values of the films with plasticizer were inversely related to the $E$ values, as reported by many other studies (Myllärinen et al., 2002; Zhang and Han, 2006a, b; Alves et al., 2007). Films with higher $E$ values over $35 \%$ (i.e. $20 \mathrm{G}, 20 \mathrm{X}, 25 \mathrm{~S}$, and $25 \mathrm{X}$ ) showed lower TS values of less than $20.00 \mathrm{MPa}$. Whereas, films with lower E values of 16-17\% (i.e. 10G, 15G, 15S, 20S, 15X, 15GS and 15GX) exhibited higher TS values ranging from 24.95 to $33.81 \mathrm{MPa}$. It is notable that the tensile properties of the films with combination of plasticizers was slightly improved, compared to glycerol alone. However, the cracks on the edges of these films were still present as some brittleness remained, but the extent was not severe. For example, 15GS and 15GX films exhibited higher TS values of 30.09 and $32.00 \mathrm{MPa}$, respectively, compared to 28.46 MPa for 15G films. Muscat et al. (2012) also observed similar results for high amylose corn starch films plasticized with the mixture of glycerol and xylitol (50:50, by weight). They were slightly stronger than the corresponding films plasticized with glycerol only (37.29 vs. 30.65 MPa). Overall, the 6HPHACS films plasticized with $15 \%(\mathrm{w} / \mathrm{w})$ glycerol provided reasonable tensile strength and flexibility. 


\section{3-3-2. FTIR spectroscopy}

FT-IR spectroscopy was used to elucidate possible molecular interactions between starch and plasticizer in films (Fig. 5). Although all films appeared to have the quite similar profiles, there were some differences in peak areas. The broad peak at $3600-3000 \mathrm{~cm}^{-1}$ (Zone 1), corresponding to stretching mode of hydroxyl groups due to water and carbohydrates (Piermaria et al., 2011), followed the order 20G HPHACS (20.29) > 20S HPHACS (5.09) > 20G HACS (2.90) > 15G HPHACS (0.61). The peak areas at 1700-1580 $\mathrm{cm}^{-1}$ (Zone 2) assigned to another water molecule (specifically, bending mode of hydroxyl groups in water molecules) (Piermaria et al., 2011), were relatively lower compared to that at $3600-3000 \mathrm{~cm}^{-1}$. The peak areas at around $1000 \mathrm{~cm}^{-1}$ (Zone 3), also recognized as water sensitive (Van Soest et al., 1995), exhibited the same trend as Zone 1 peaks. The 20G HPHACS films contained larger amount of water molecules than the 20S HPHACS films. This might be attributed to the higher hygroscopic character of glycerol than sorbitol, which strongly interacts with water (Laohakunjit and Noomhorm, 2004). This is in agreement with the moisture content data presented in Fig. 6, indicating sorbitol-plasticized films containing less moisture.

The increase of glycerol content from 15 to $20 \%$ (w/w of starch) made more water molecules available for HPHACS films than native HACS films, indicating increased hydrophilicity due to hydroxypropylation. Moisture content of HPHACS films was higher than that of HACS films (12.00 vs. $7.51 \%$, Fig. 6), which gradually increased with increase in hydroxypropyl groups. The moisture contents of 3, 6 and 12 HPHACS films with $20 \%$ glycerol (w/w of starch) were $11.59 \%, 12.00 \%$ and $14.13 \%$, respectively (data not shown).

The FTIR results discussed above suggest intermolecular interaction between starch and 409 plasticizer through the hydroxyl groups. Possibly, the most extensive interaction may occur for 
the 20G 6HPHACS films containing more water molecules among tested samples. This interaction reduced the free volume for starch mobility, resulting in rigid films. As seen in Fig. 4, the 20G 6HPHACS films had the lowest TS (15.66 MPa), whereas, the strongest TS (28.45 $\mathrm{MPa}$ ) for $15 \mathrm{G} 6 \mathrm{HPHACS}$ film could be attributed to the lack of water molecules in films.

\section{3-3-3. Barrier properties}

Barrier properties of 6HPHACS films against water and oxygen are presented in Fig. 7. Water vapor permeability (WVP) for 20G 6HPHACS films was higher than for 15G 6HPHACS films- 0.04 and $0.03 \mathrm{~g} \mathrm{~mm} \mathrm{~m}^{-2} \mathrm{day}^{-1} \mathrm{kPa}^{-1}$ - respectively. This suggests that more glycerol in film contributed to higher water vapor permeability, perhaps due to the hydrophilic nature of glycerol for the presence of hydroxyl groups (-OH). The existence of 3 hydroxyl groups (-OH) in glycerol influences the solubility and hygroscopic characteristics of the film (Isotton et al., 2015).

Oxygen permeability of films showed the similar pattern. The 20G 6HPHACS film had higher oxygen permeability (OP) than 15G 6HPHACS film (267.52 vs. $230.59 \mathrm{~cm}^{3} \mu \mathrm{m} \mathrm{m}^{-2}$ day $\left.^{-1} \mathrm{kPa}^{-1}\right)$. Similar to the results reported in literatures increasing glycerol content increased oxygen permeability as well (Mali et al., 2004; Banker, 1966; McHugh and Krochta, 1994). The water barrier properties of 6HPHACS films can be considered 'superior' (less than $0.1 \mathrm{~g}$ $\mathrm{mm} \mathrm{m}^{-2}$ day $^{-1} \mathrm{KPa}^{-1}$ ) based on classification suggested by Han (2014), which is comparable to commercial plastics. However, its oxygen barrier properties were marginal $\left(100-1000 \mathrm{~cm}^{3} \mu \mathrm{m}\right.$ $\mathrm{m}^{-2}$ day $^{-1} \mathrm{KPa}^{-1}$ ). Superior oxygen permeability was less than $10 \mathrm{~cm}^{3} \mu \mathrm{m} \mathrm{m}^{-2} \mathrm{day}^{-1} \mathrm{KPa}^{-1}$. The oxygen permeability of the 6HPHACS films was within high density polyethylene (HDPE, $100-1000 \mathrm{~cm}^{3} \mu \mathrm{m} \mathrm{m}^{-2} \mathrm{day}^{-1} \mathrm{KPa}^{-1}$ ) range but much higher than ethylene vinyl alcohol (EVOH, $\left.<10 \mathrm{~cm}^{3} \mu \mathrm{m} \mathrm{m}^{-2} \mathrm{day}^{-1} \mathrm{KPa}^{-1}\right)$. 


\section{Conclusions}

Low degree of hydroxypropylation could effectively reduce the brittleness in highamylose corn starch films with minimal plasticizer required. The hydroxypropylation played important role in decreasing the intermolecular interactions between starch chains like an 439 internal plasticizer, thereby, effectively increasing flexibility of the films. After the hydroxypropylation, only the minimal amount of plasticizer (approximately $20 \%$ by weight)

441

442

443

444

445

446

447

\section{Acknowledgement}

This research was supported by Center for Bioplastics And Biocomposites $\left(\mathrm{CB}^{2}\right)$ at Iowa State University. We thank the USDA Agricultural Research Service at Peoria, IL, and VISKASE ${ }^{\circledR}$ Companies, Inc. for technical assistance with barrier properties.

was required for obtaining the HACS film with good flexibility. Based on our results, hydroxypropylation with $6 \%$ propylene oxide (w/w of starch) and $20 \%$ glycerol (w/w of starch) was the optimal condition for solvent casting of starch films with better mechanical properties. 


\section{References}

Alves, V. D., Mali, S., Beléia, A., Grossmann, V. E., 2007. Effect of glycerol and amylose enrichment on cassava starch film properties. J. Food Eng, 78, 941-946.

ASTM, 2002. Standard test method for tensile properties of thin plastic sheeting, D882-02 annual book of ASTM. Philadelphia, PA: American Society for Testing and Meterials.

ASTM, 2010. Standard test method for oxygen gas transmission rate through plastic film and sheeting using a coulometric sensor, D3985-05 annual book of ASTM. Philadelphia, PA: American Society for Testing and Meterials.

ASTM, 2013. Standard test method for water vapor transmission of organic coating film, D1653-13 annual book of ASTM. Philadelphia, PA: American Society for Testing and Meterials.

Bader, H. G., Göritz, D., 1994. Investigations on high amylose corn starch films. Part 3: Stress strain behavior. Starch/Stärke, 46, 435-439.

Bae, S. O., Lim, S.-T., 1998. Physical properties of extruded strands of hydroxypropylated normal and high-amylose corn starch. Cereal Chem., 75(4), 449-454.

Banker, G. S., 1966. Film coating, theory and practice. J. Pharm. Sci., 55, 81-89.

Bär, A., 1991. Xylitol. In Gelardi RC, O’Brien-Nabors L, editors. Alternative sweetners. $2^{\text {nd }}$ ed. New York: Marcel Dekker. Ch. 19. P 349-379.

Bertuzzi, M. A., Castro Vidaurre, E. F., Armanda, M., Gottifredi, J. C., 2007. Water vapor permeability of edible starch based films. J. Food Eng., 80, 972-978.

Briston, J. H., 1988. Plastic films. New York: John Wiley and Sons.

Chang, Y. P., Karim, Abd., Seow, C. C., 2006. Interactive plasticizing-antiplasticizing effects of water and glycerol on the tensile properties of tapioca starch films. Food Hydrocoll., $20,1-8$. 
Chaudhary, A. L., Torley, P.J., Halley, P. J., McCaffery, N., Chaudhary, D. S., 2009. Amylose content and chemical modification effects on thermoplastic starch from maize-Processing and characterization using conventional polymer equipment. Carbohyd. Polym., 78, 917925.

Chiellini, E., Cinelli, P., Ilieva, V. I., Imam, S. H., Lawton, J. L., 2009. Environmentally compatible foamed articles based on potato starch, corn fiber, and poly (vinyl alcohol). J. Cell. Plast., 45, 17-32.

Choi, S. G., Kerr, W. L., 2004. Swelling characteristics of native and chemically modified wheat starches as a function of heating temperature and time. Starch/Stärke, 56, 181-189.

Choi, Y. J., Lim, S.-T., Im, S.-S., 1997. Preparation of hydroxypropylated corn starch at high degrees of substitution in aqueous alcohol, and pasting properties of the starch. Food Biotechnol., 6, 118-121.

Cooke, D., Gidley M. J., 1992. Loss of crystalline and molecular order during starch gelatinization: Origin of the enthalpic transition. Carbohye. Res., 227, 103-112.

Dean, K. M., Petinakis, E., Goodall, L., Miller, T., Yu, L., Wright, N., 2011. Nanostabillization of thermally processed high amylose hydroxypropylated starch films. Carbohyd. Polym., $86,652-658$.

Food Chemicals Codex, National Academy of Sciences, $2^{\text {nd }}$ edition, 1972, P. 328.

French, D., 1984. Organization of starch granules. In Starch Chemistry and Technology. R. L. Whistler, J. N. BeMiller, and E. F. Paschall, eds. Academic Press: Orlando, FL, pp. 183247.

Ghasemlou, M., Aliheidari, N., Farmi, R., Shojaee-Aliabadi, S., Keshavarz, B., Cran, M. J., Khaksar, R., 2013. Physical, mechanical and barrier properties of corn starch films incorporated with plant essential oils. Carbohyd. Polym., 98(1), 1117-1126. 
506 Gibson, L. J., Ashby, M. F., 1988. Cellular solids: structure and properties. Oxford, U. K.: Pergamon Press. P 42-68.

508

509

510

511

512

513

514

515

516

517

518

519

520

521

522

523

524

525

526

527

528

529

Gilfillan, W. N., Sopade, P. A., Doherty, W. O. S., 2013. Moisture uptake and tensile properties of starch-sugar cane fibre films. Int. Sugar J., 115 (1369), 23-27.

Gontard, N., Guilbert, S., Cuq, JL., 1993. Water and glycerol as plasticizers affect mechanical and water vapor barrier properties of edible wheat gluten films. J. Food Sci., 58, 206-211.

Gray, J. A., BeMiller, J. N., 2005. Influence of reaction conditions on the location of reactions in waxy maize starch granules reacted with a propylene oxide analog at low substitution levels. Carbohyd. Polym., 60, 147-162.

Griffin, WG., Lynch, MJ., 1980. Polyhydric alcohols. In: Furia TE, editor. Handbook of food additives. Vol. 2. $2^{\text {nd }}$ ed. Ohio: CRC Press. P 431-455.

Han, J. H., 2014. Edible films and coatings: A review. Innovations in Food Packaging, chapter $9,213-255$.

Isotton, F. S., Bernardo, G. L., Baldasso, C., Rosa, L. M., Zeni, M., 2015. The plasticizer effect on preparation and properties of etherified corn starch films. Ind. Crops Prod., 76, 717724.

Jangehud, A., Chinnan, M. S., 1999. Properties of peanut protein film: sorption isotherm and plasticizer effect. LWT - Food Sci. Technol., 32, 89-94.

Jansson, A., Järnström, L., 2005. Barrier and mechanical properties of modified starches. Cellulose, 12, 423-433.

Johnson, D. P., 1969. Spectrophotometric determination of the hydroxypropyl group in starch ethers. Anal. Chem., 41, 859-860.

Kim, H.-S., Choi H.-S., Kim, B.-Y., Baik, M.-Y., 2011. Ultra high pressure (UHP)-assisted hydroxypropylation of corn starch. Carbohyd. Polym., 83, 755-761. 
Klucinec, J. D., Thompson, D. B., 1998. Fractionation of high amylose maize starches by differential alcohol precipitation and chromatography of the fraction. Cereal Chem., 75, 887-896.

Lafargue, D., Pontoire, B., Buléon, A., Doublier, L. J., Lourdin, D., 2007. Structure and mechanical properties of hydroxypropylated starch films. Biomacromolecules, 8(12), 3950-3958.

Lai, H. M., Padua, G. W., 1997. Properties and microstructure of plasticized zein films. Cereal Chem., 74, 771-775.

Laohakunjit, N., Noomhorm, A., 2004. Effect of plasticizers on mechanical and barrier properties of rice starch film. Starch/Stärke, 56, 348-356.

Li, X., Qiu, C., Ji, N., Sun, C., Xiong, L., Sun, Q., 2015. Mechanical, barrier and morphological properties of starch nanocrystals-reinforced pea starch films. Carbohyd. Polym., 121, 155162.

Liu, H., Yu, L., Xie, F., Chen, L., 2006. Gelatinization of corn starch with different amylose/amylopectin content. Carbohyd. Polym., 65, 357-363.

Lopez, O.V., Garcia, M. A., 2012. Starch films from a novel (Pachyrhizus ahipa) and conventional sources: Development and characterization. Mat. Sci. Eng. C, 32, 1931-1940.

Mali, S., Grossmann, M. V. E., Garcia, M. A., Martino, M. N., Zaritzky, N. E., 2004. Barrier, mechanical and optical properties of plasticized yam starch films, Carbohyd. Polym., 56, 129-135.

Mali, S., Grossmann, M. V. E., Garcia, M. A., Martino, M. N., Zaritzky, N. E., 2005a. Mechanical and thermal properties of yam starch films, Food Hydrocoll., 19, 157-164.

Mali, S., Sakanaka, L. S., Yamashita, F., Grossmann, M.V. E., 2005b. Water sorption and mechanical properties of cassava starch films and their relation to plasticizing effect. 
555

556

557

558

559

560

561

562

563

564

565

566

567

568

569

570

571

572

573

574

575

576

577

McHugh, T. H., Krochta, J. M., 1994. Sorbitol- vs glycerol-plasticized whey protein edible films: integrated oxygen permeability and tensile property evaluations. J. Agr. Food Chem., 42, 841-845.

Müller, C. M. O., Yamashita, F., Laurindo, J. B., 2008. Evaluation of the effects of glycerol and sorbitol concentration and water activity on the water barrier properties of cassava starch films through a solubility approach. Carbohyd. Polym., 72, 82-87.

Muscat, D., Adhikari, B., Adhikari, R., Chaudhary, D. S., 2012. Comparative study of film forming behavior of low and high amylose starches using glycerol and xylitol as plasticizers. J. Food Eng., 109, 189-201.

Myllärinen, P., Partanen, R., Seppala, J., Forssell, P., 2002. Effect of glycerol on behavior of amylose and amylopectin films. Carbohyd. Polym., 50, 355-361.

Perera, C., Hoover, R., Martin, A. M., 1997. The effect of hydroxypropylation on the structure and physicochemical properties of native, defatted and heat-moisture treated potato starches. Food Res. Int., 30, 235-247.

Phan, T. D., Debeaufort, F., Luu, D., Voilley, A., 2005. Functional properties of edible agarbased and starch-based films for food quality preservation. Journal of Agricultural and Food Chem., 53 (4), 973-981.

Piermaria, J., Bosch, A., Pinotti, A., Yantorno, O., Garcia, M. A., Abraham, A. G., 2011. Kefiran films plasticized with sugars and polyols: water vapor barrier and mechanical properties in relation to their microstructure analyzed by ATR/FT-IR spectroscopy. Food Hydrocoll., 25, 1261-1269.

Seow, C. C., Thevamalar, K., 1993. Internal plasticization of granular rice starch by hydroxypropylation: effects on phase transition associated with gelatinization. 
Shanks, R., Kong, I., 2012. Thermoplastic starch. Thermoplastic Elastomers, Chapter 6, 95116.

581

Shogren, R. L., 1992. Effect of moisture content on the melting and subsequent physical aging of cornstarch. Carbohyd. Polym., 19 (2), 83-90.

Souza, R. C. R., Andrade, C. T., 2002. Investigation of the gelatinization and extrusion processes of corn starch. Adv. Polym. Tech., 21, 1-8.

Thuwall, M., Kuthanova, V., Boldizar, A., Rigdahl, M., 2006. Extrusion processing of high amylose potato starch materials. Carbohyd. Polym., 65, 441-446.

Tsuzuki, T., 1968. Hydroxypropyl starch ether. US 3378546 A.

Van Soest, J. J. G., Benes, K., de Wit, D., 1996. The influence of acid hydrolysis of potato starch on the stress-strain properties of thermoplastic starch. Carbohyd. Polym., 71, 583590.

Van Soest, J. J. G., Tournois, H., de Wit, D., Vliegenthart, J.F. G., 1995. Short-range structure in (partially) crystalline potato starch determined with attenuated total reflectance FourierTransform IR spectroscopy. Carbohyd. Res., 279, 201-214.

Wexler, A., Hasegawa, S., 1954. Relative humidity-temperature relationships of some saturated salt solutions in the temperature range $0^{\circ} \mathrm{C}$ to $50^{\circ} \mathrm{C}$. J. Re. Natl. Stand., 53(1), 2512.

Woggum, T., Sirivongpaisal, P., Wittaya, T., 2015. Characteristics and properties of hydroxypropylated rice starch based biodegradable films. Food Hydrocoll., 50, 54-64.

Wootton, M., Manatsathit, A., 1983. The influence of molar substitution on the water binding capacity of hydroxypropyl maize starches. Starch/Stärke, 35, 92-94.

Wootton, M., Manatsathit, A., 1984. The influence of molar substitution on the gelatinization of hydroxypropyl maize starches. Starch/Stärke, 36, 207-208. 
Zdrahala, R. J., 1997. Thermoplastic starch revisited structure/property relationship for “dialed- in” biodegradability. Macromol. Symp., 123, 113-121.

Zhang, N., Liu, H., Yu, L., Liu, X., Zhang, L., Chen, L., Shanks, R., 2013a. Developing gelatinstarch blends for use as capsule materials. Carbohyd. Polym., 92, 455-461.

Zhang, N., Liu, H., Yu, L., Shanks, R., Petinakis, E., Liu, H., 2013b. Phase composition and interface of starch-gelatin blends studied by synchrotron FTIR micro-spectroscopy. Carbohyd. Polym., 95, 649-653.

Zhang, Y., Han, J. H., 2006a. Mechanical and thermal characteristics of pea starch films plasticized with monosaccharides and polyols. J. Food Sci., 71 (2), E109-E118.

Zhang, Y., Han, J. H., 2006b. Plasticization of pea starch films with monosaccharides and polyols. J. Food Sci., 71 (6), E253-E261.

Zhang, Y., Rempel, C., McLaren, D., 2014b. Thermoplastic starch. Innovations in Food 


\section{Figure captions}

617

618

619

620

621

622

623

624

625

626

627

628

629

630

631

632

633

634

635

636

637

638

639

Fig. 1. Appearance of cast-films made from native (a), and hydroxypropylated (b) corn starches. In (b), high amylose corn starch was hydroxypropylated with propylene oxide (PO) at 3-12\% (starch weight basis, [s.w.b.]). All films were plasticized with $20 \%$ glycerol (s.w.b.).

Fig. 2. Thermal properties of HPHACS with PO of 3-12\% (s.w.b.).

Fig. 3. Appearance of 6HPHACS films with various plasticizing conditions. G, glycerol; S, sorbitol; X, xylitol; GS, glycerol and sorbitol (50:50); GX, glycerol and xylitol (50:50).

Fig. 4. Thickness and mechanical properties (TS and E) of 6HPHACS films depending on the plasticizing conditions. The data sharing the same alphabet are not significantly different, $p<0.05$.

Fig. 5. ATR-FTIR spectra of HACS and 6HPHACS films. The numbers in parentheses represent the total relative absorption intensity of the bands assigned to water molecules (Zone 1, 2, and 3).

Fig. 6. Moisture contents of HACS and 6HPHACS films. The data sharing the same alphabet are not significantly different, $p<0.05$.

Fig. 7. Water vapor permeability and oxygen permeability of 6HPHACS films. The data sharing the same alphabet are not significantly different, $p<0.05$.

(1)


640 Table lists

641

642 Table 1. Hydroxypropyl group levels (\%), molar substitution (MS), and reaction efficiency (\%)

643 for hydroxypropylation of high amylose corn starches (HPHACS). ${ }^{\mathrm{A}}$

644 Table 2. Thickness, transparency, and mechanical properties of cast-films made from HPHACS with PO of $3-12 \%$ (s.w.b.). ${ }^{\mathrm{A}}$

646 
(a) Native starches

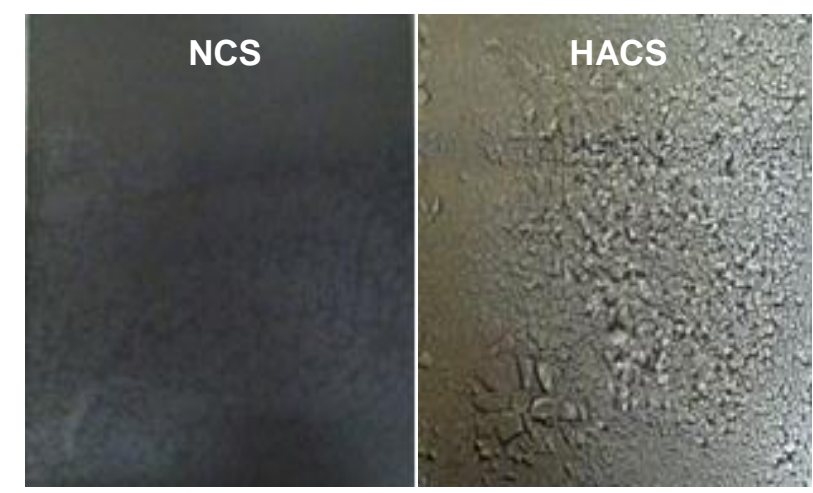

(b) Hydroxypropylated starches

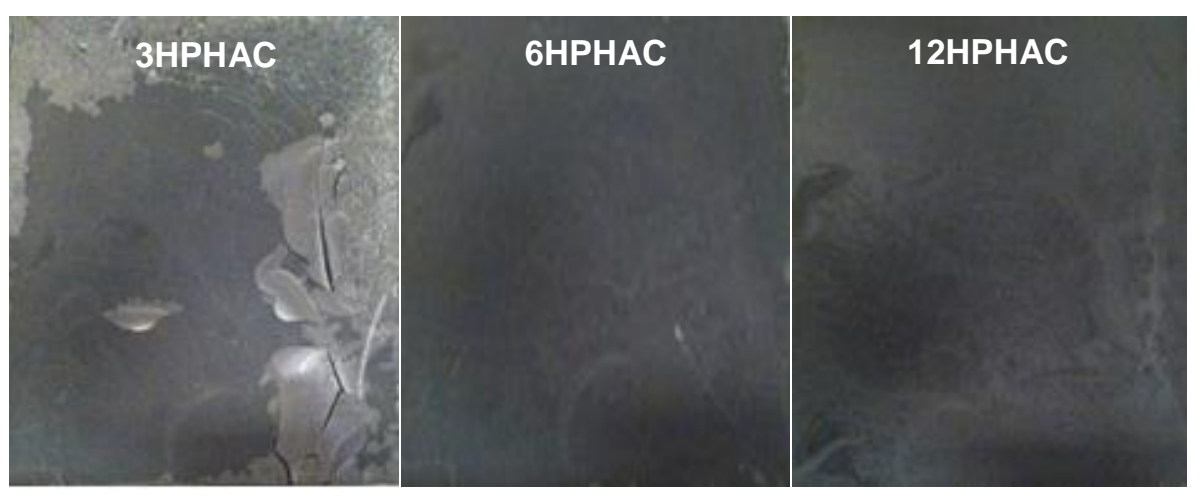

Fig. 1. 


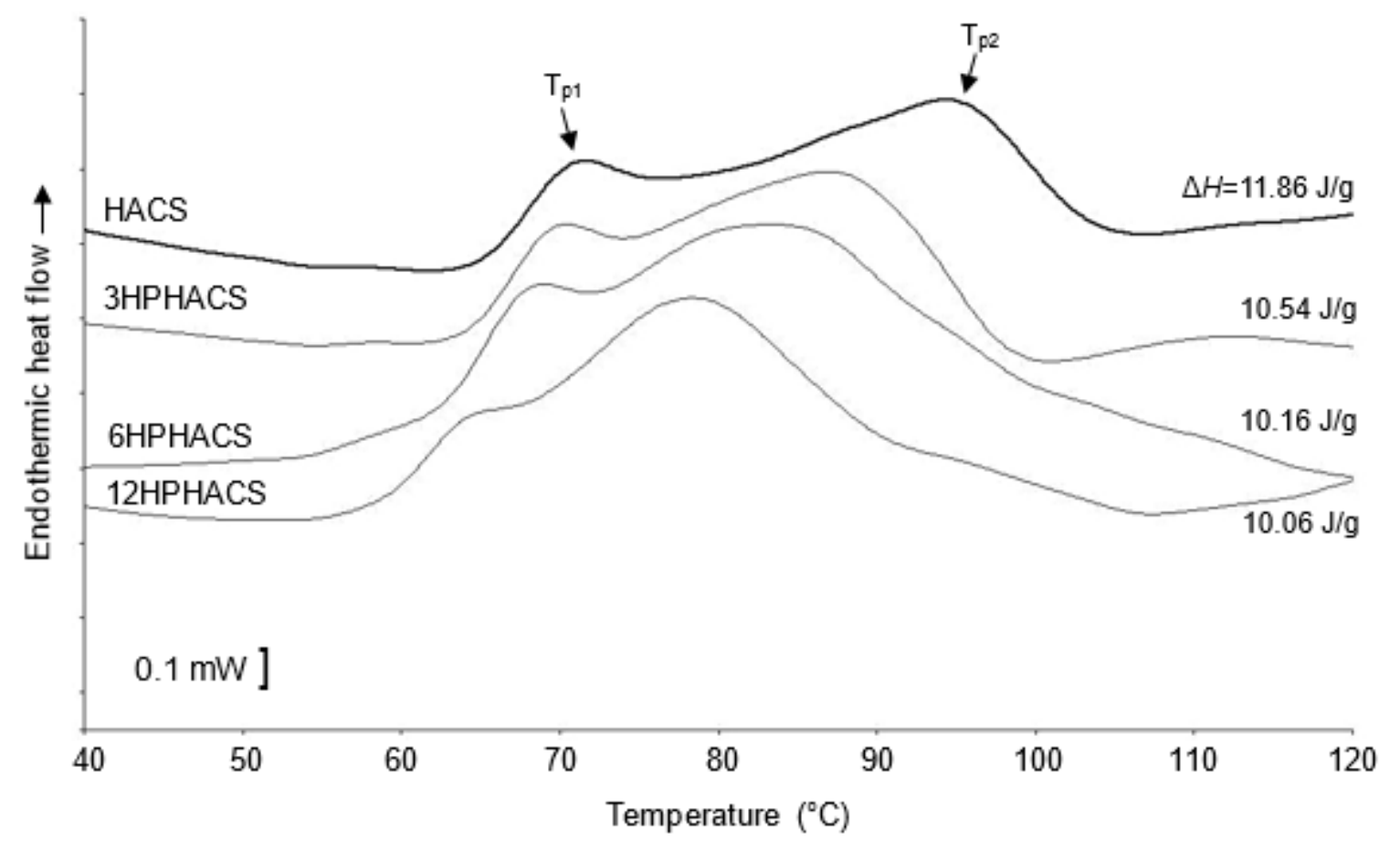

Fig. 2. 
Plasticizer concentration

$10 \%(w / w)$

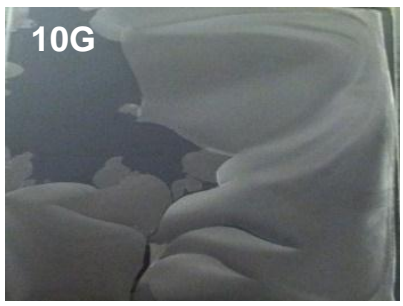

$15 G$

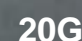

$20 \mathrm{G}$

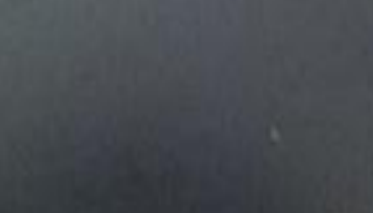

205

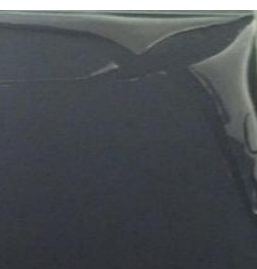

$20 x$

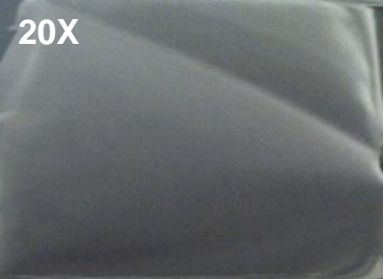

$15 \%(w / w)$

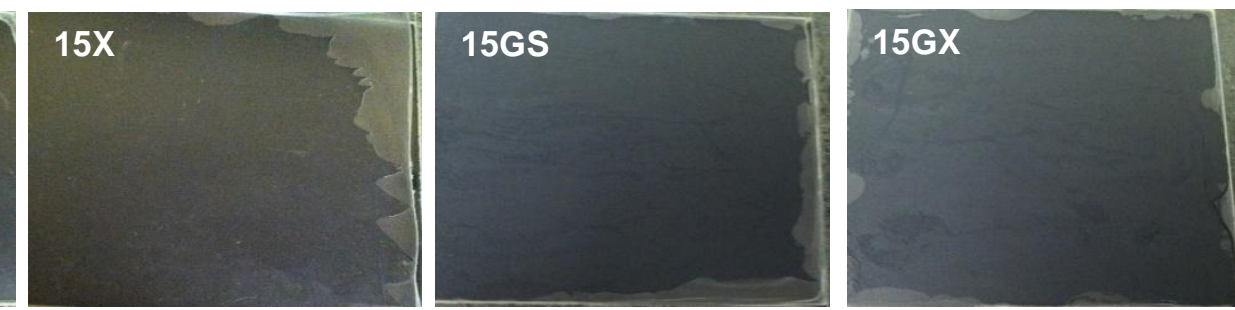

$25 \%(w / w)$

$25 S$

$25 X$

Fig. 3. 

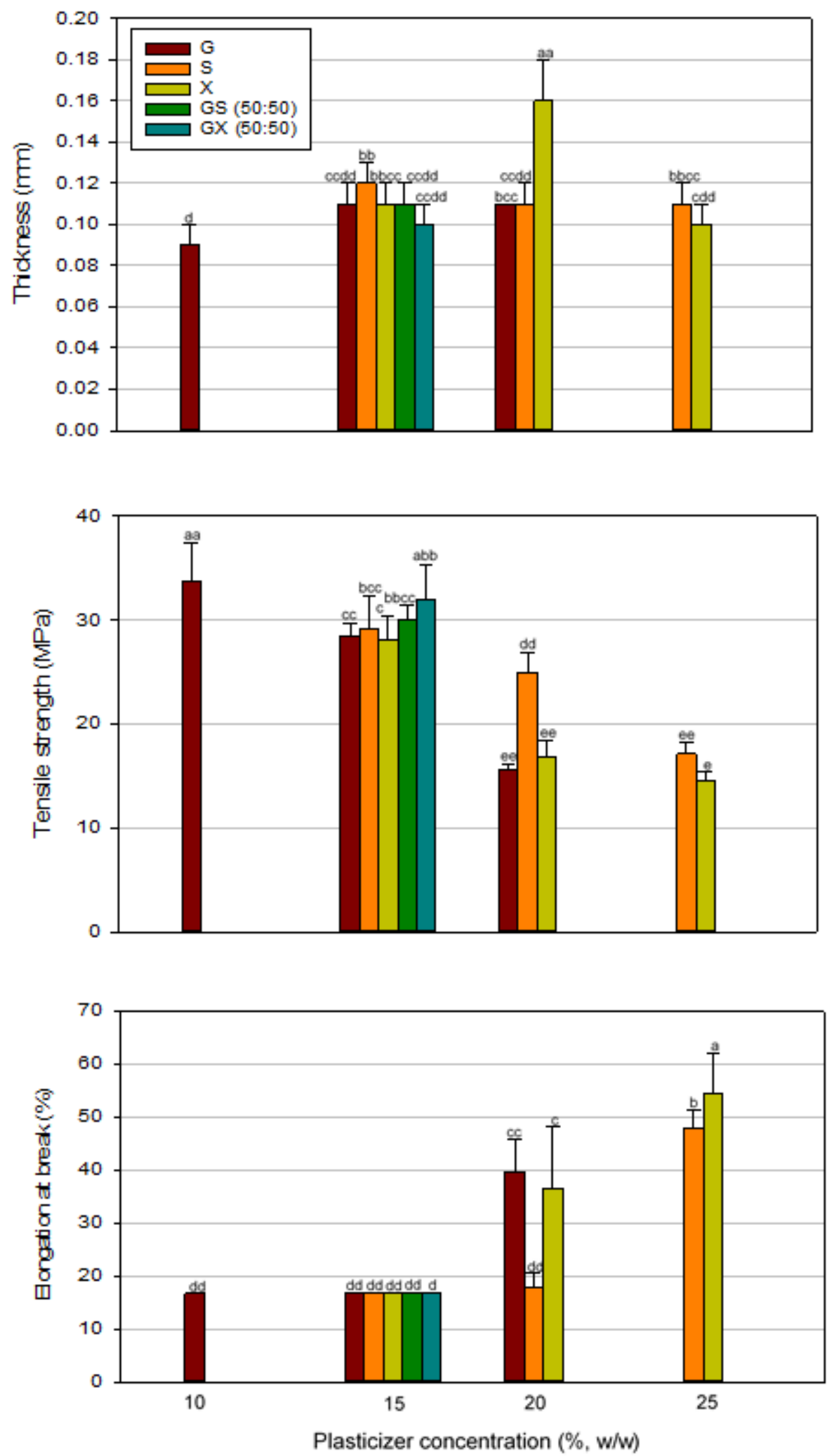

Fig. 4. 


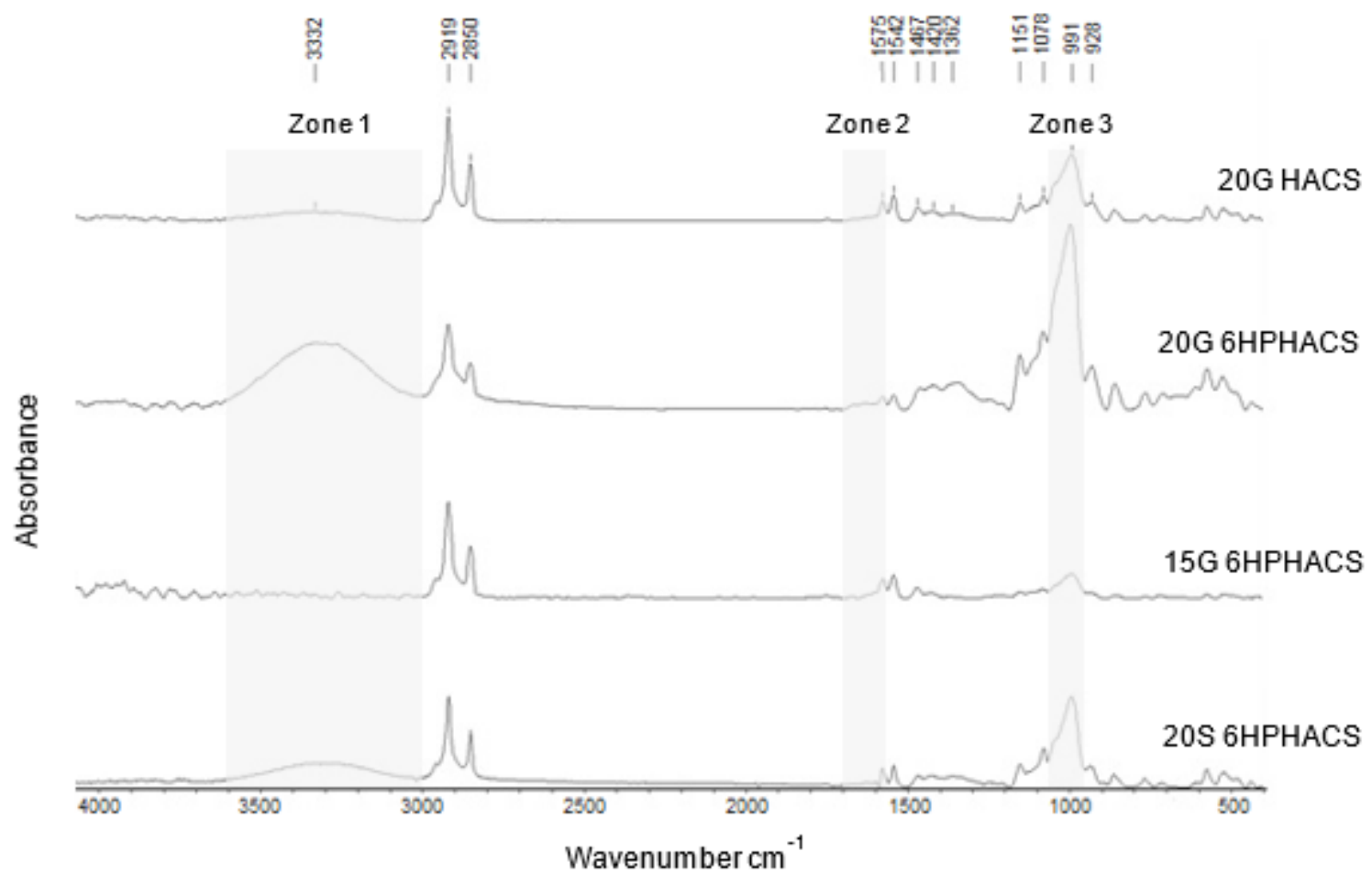

Fig. 5. 


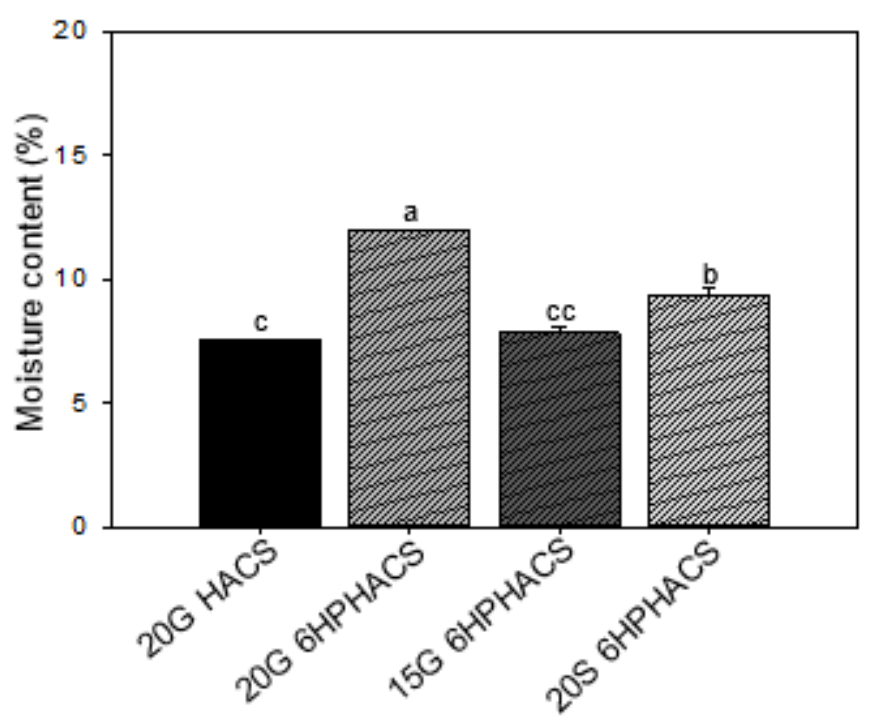

Fig. 6. 


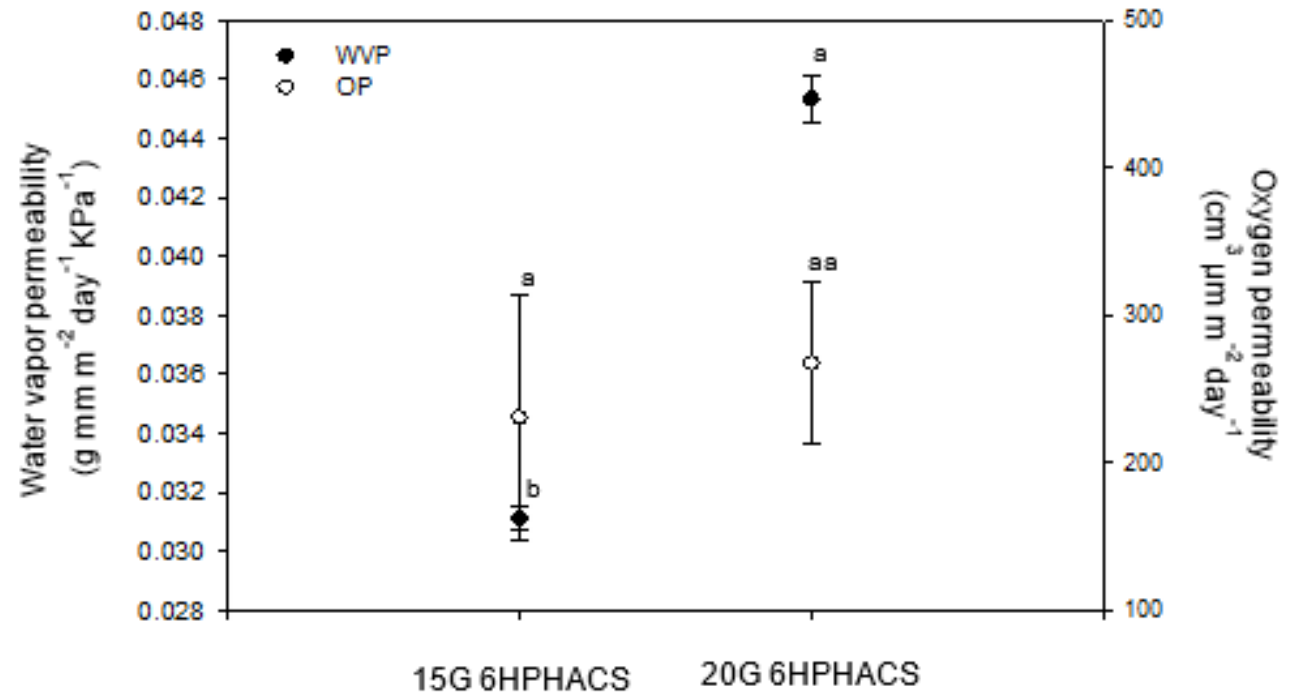

Fig. 7. 
Table 1. Hydroxypropyl group (\%), molar substitution (MS), and reaction efficiency (\%) of hydroxypropylated high amylose corn starches (HPHACS). ${ }^{\mathrm{A}}$

\begin{tabular}{lllll}
\hline Starch & $\begin{array}{l}\text { Propylene oxide } \\
\text { concentration }(\%, \text { starch } \\
\text { weight basis) }\end{array}$ & $\begin{array}{l}\text { Hydroxypropyl } \\
\text { group (\%) }\end{array}$ & $\begin{array}{l}\text { Molar } \\
\text { substitution } \\
\text { (MS) }\end{array}$ & $\begin{array}{l}\text { Reaction } \\
\text { efficiency }(\%)^{\mathrm{B}}\end{array}$ \\
\hline HACS & 0 & $0.31 \pm 0.14^{\mathrm{d}}$ & $0.01 \pm 0.00^{\mathrm{d}}$ & - \\
3HPHACS & 3 & $1.38 \pm 0.05^{\mathrm{c}}$ & $0.04 \pm 0.00^{\mathrm{c}}$ & 49.38 \\
6HPHACS & 6 & $2.50 \pm 0.04^{\mathrm{b}}$ & $0.07 \pm 0.00^{\mathrm{b}}$ & 43.20 \\
12HPHACS & 12 & $5.08 \pm 0.07^{\mathrm{a}}$ & $0.15 \pm 0.00^{\mathrm{a}}$ & 46.29 \\
\hline
\end{tabular}

\footnotetext{
${ }^{\text {A }}$ Values followed by the same superscripts in the same column are not significantly different $(p<0.05)$.

${ }^{\mathrm{B}}$ Reaction efficiency $(\%)=(\mathrm{MS} \times$ starch weight $(\mathrm{g}) \times 100) /($ moles of added propylene oxide $\times 162)($ Choi et al., 1997$)$
} 
Table 2. Thickness, transparency, and mechanical properties of cast-films made from HPHACS with propylene oxide of $3-12 \%(\mathrm{w} / \mathrm{w}){ }^{\mathrm{A}}$

\begin{tabular}{lllll}
\hline \multirow{2}{*}{$\begin{array}{l}\text { Film } \\
\text { composition }\end{array}$} & $\begin{array}{l}\text { Thickness } \\
(\mathrm{mm})\end{array}$ & \multicolumn{2}{l}{ Mechanical properties } & \multirow{2}{*}{$\begin{array}{c}\text { Transparency } \\
(\text { A600/mm })\end{array}$} \\
\cline { 3 - 4 } & & TS $(\mathrm{MPa})$ & $E(\%)$ & \\
\hline 20G HACS & $0.12 \pm 0.01^{\mathrm{aa}}$ & $18.90 \pm 1.05^{\mathrm{a}}$ & $28.17 \pm 7.97^{\mathrm{c}}$ & $2.04 \pm 0.04^{\mathrm{aa}}$ \\
20G 3HPHACS & $0.11 \pm 0.01^{\mathrm{aa}}$ & $15.98 \pm 0.61^{\mathrm{bb}}$ & $37.55 \pm 3.90^{\mathrm{b}}$ & $1.88 \pm 0.05^{\mathrm{a}}$ \\
20G 6HPHACS & $0.11 \pm 0.00^{\mathrm{aa}}$ & $15.66 \pm 0.50^{\mathrm{b}}$ & $39.64 \pm 6.02^{\mathrm{bb}}$ & $1.29 \pm 0.11^{\mathrm{bb}}$ \\
20G 12HPHACS & $0.10 \pm 0.02^{\mathrm{a}}$ & $8.85 \pm 0.90^{\mathrm{c}}$ & $63.37 \pm 4.22^{\mathrm{a}}$ & $1.26 \pm 0.19^{\mathrm{b}}$ \\
\hline
\end{tabular}

20G, 20\% glycerol (w/w, dry starch basis); TS, tensile strength; $E$, elongation at break.

${ }^{\mathrm{A}}$ Values followed by the same superscripts in the same column are not significantly different $(p<0.05)$. 